\title{
Sanayi Devrimleri, Kurtuluş Yılmaz Genç, Metin Çakıroğlu, Cevdet Özmen ve Gökhan Karadirek, 2019, s. 228, ISBN: 978-605-7809-63-6. Gece Akademi, Ankara.
}

Öğr. Gör. Mehmet Akif Kara

ORCID ID: $\underline{\text { https://orcid.org/0000-0003-4308-9933 }}$

Giresun Üniversitesi, Eynesil Kamil Nalbant Meslek Yüksekokulu, Finans Bankacılık ve Sigortacılık Bölümü, Giresun - TÜRKIYE

\section{Makale Geçmişi}

Geliş: 20.08.2019

Kabul: 25.09.2019

On-line Yayın: 30.09.2019

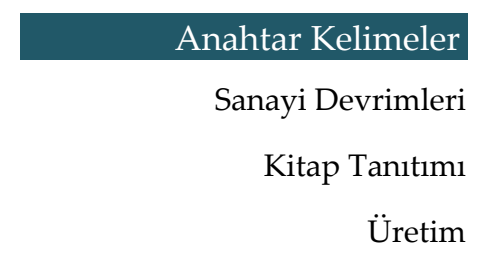

\section{$\mathrm{Oz}$}

Kitap Dĕgerlendirme

\section{DOI:}

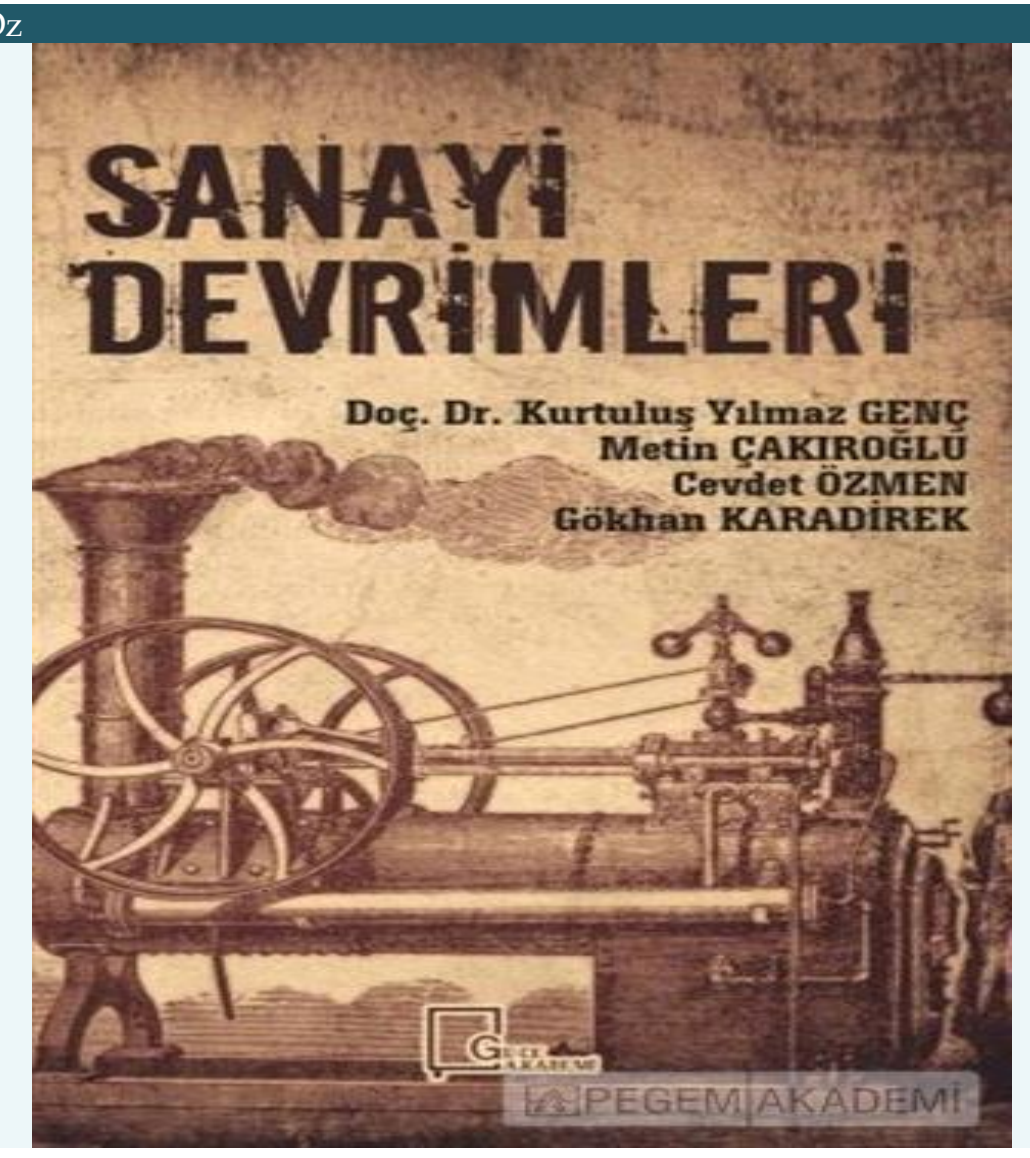

Atıf Bilgisi / Reference Information

Kara, M. A. (2019). Sanayi Devrimleri, Kurtuluş Yılmaz Genç, Metin Çakıroğlu, Cevdet Özmen ve Gökhan Karadirek, 2019, s. 228, ISBN: 978-605-7809-63-6. Gece Akademi, Ankara. Jass Studies- The Journal of Academic Social Science Studies, Number: 76, Autumn, p. 557-561. 


\title{
Sanayi Devrimleri, Kurtuluş Yılmaz Genç, Metin Çakıroğlu, Cevdet Özmen ve Gökhan Karadirek, 2019, p. 228, ISBN: 978-605-7809-63-6. Gece Akademi, Ankara.
}

\author{
Lect. Mehmet Akif Kara
}

Giresun Üniversitesi, Eynesil Kamil Nalbant Vocational School, Finans Bankacılık ve Sigortacılık Bölümü, Giresun - TURKEY

\section{Artcile History}

Submitted:20.08.2019

Accepted: 25.09.2019

Published Online: 30.09.2019

Key Words

Industrial Revolutions

Book Review

Production

Book Review

\section{DOI:}

http://dx.doi.org/10.29228/JASSS.37812

\section{Abstract}

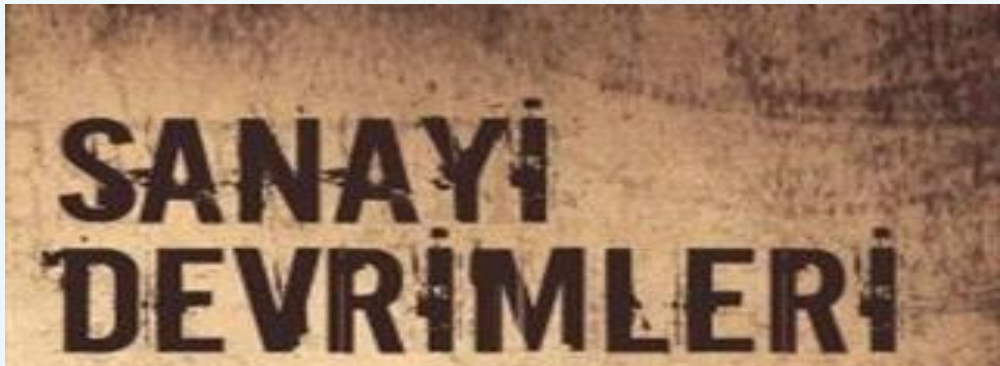

Doç. Dr. Kurtuluş Yulmaz GENę Metin CAKIROĞLU Cevdet ÖZMEN Gökhan KARADIREK

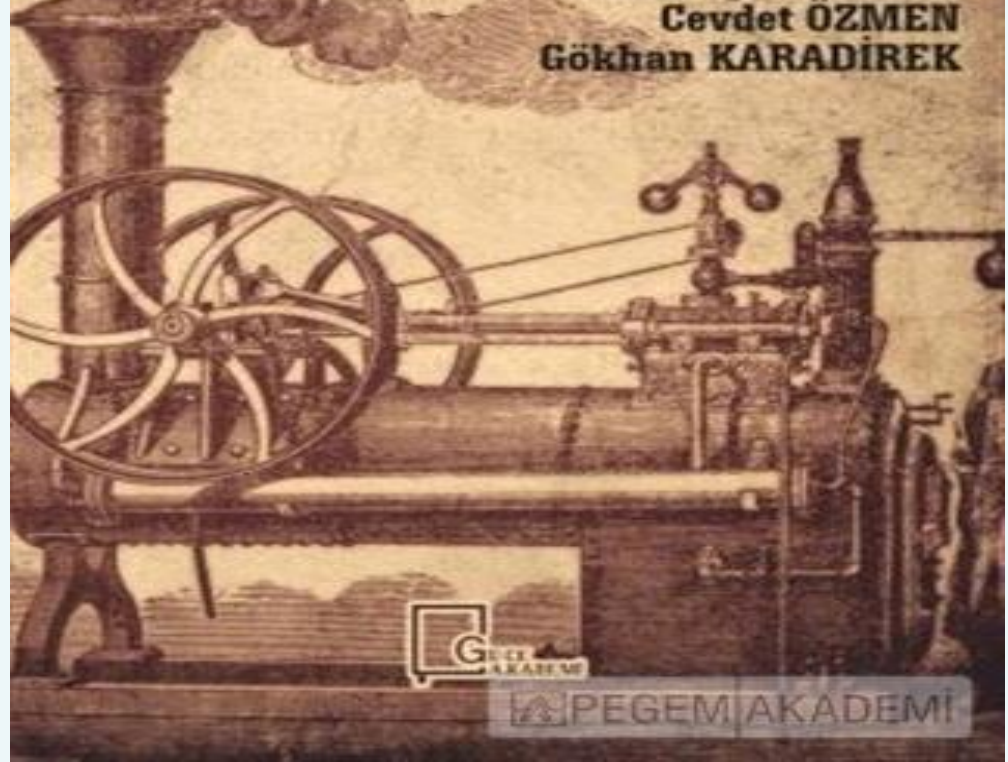


Dünya tarihinin en önemli kırılma noktalarını oluşturan ve bu bağlamda insanlığın son 300 yıllık gelişimini de yansıtan sanayi devrimleri bir çok farklı noktadan ele alınmaktadır. Günümüzde, hala daha devam eden bir süreç olarak değerlendirilmesi gereken sanayi devrimleri aynı zamanda tartışmaları ve yankıları akademik-bilimsel alanda hala süren Endüstri 4.0 gibi devrim süreçlerini de barındırmaktadır. Bir yanıyla tarihsel bir süreci kapsarken bir yanıyla da geleceğe ait bir projeksiyon sunmaktadir.

İnsanlığın gelişimi noktasında hemen her alanda yaşanan değişikliklerin temelini teşkil eden Sanayi Devrimleri aynı zamanda feodalizmden kapitalizme geçişin başlangıcını oluşturmakta ve kapitalizmin farklı veçhelerini de üretmektedir.

İlk sanayi devrimi su ve buhar gücünü kullanarak mekanik üretim sistemleri ile ortaya çıkmış, ikinci sanayi devrimi ise elektrik gücünün yardımıyla seri üretim ile gerçekleşmiştir. Ücncü Sanayi devrimi ise dijital devrim, Bilgi Teknolojilerinin gelişmesi ile üretimi otomatik hale getirmiştir. Yapay zeka, bulut teknolojisi, siber güvenlik vb. Tartışmaların yapıldığı dönem ise 4 . sanayi devrimine tekabül etmektedir.

Giresun Üniversitesi İktisadi ve İdari Bilimler Fakültesi İşletme Bölümü Öğretim Üyesi Doç.Dr. Kurtuluş Yılmaz Genç editörlügünnde Arş.Gör. Metin Çakıroğlu, Öğr.Gör. Cevdet Özmen ve Öğr.Gör. Gökhan Karadirek'in katkılarıyla hazırlanan Sanayi Devrimleri kitabı da bu bağlamda değerlendirilip, tartışılması gereken bir çalışma olarak karşımıza çıkmaktadır. Uluslararası yayınevi statüsünde bulunan Gece Akademi yayınları tarafından basılan çalışma, 4 bölüm ve 228 sayfadan oluşmaktadır.

Çalışmanın ilk bölümünde Metin Çakıroğlu ve Gökhan Karadirek 1.Sanayi devrimi sürecini çeşitli başlıklar halinde, bütünlüklü olarak ele almışlardır (s. 13-108). Yazarlar, Sanayi devrimi kavramının ortaya konulmasını, tarihsel süreci, etkilerini tartışmış ve okuyucuya aktarmıştır. Özellikle, Sanayi Devriminin İngiltere'de ortaya çıkışının nedenleri, teknolojik gelişmelerin üretim ve yönetim alanlarında yarattığı köklü değişimler ele alınmıştır. Teknolojide yaşanan inanılmaz gelişimin etkisi ile birlikte sosyal, ekonomik ve toplumsal yaşamda bir çok paradigma değişmiş ve geçmişe ait bir çok kurum/kültür vb. "tarihe" ait hale gelmiştir. Yazarlar, Sanayi devriminin meydana gelmesine neden olan "gelişmeleri" ele almışlardır (s. 17).

$\mathrm{Bu}$ bağlamda; özellikle nüfus artışı, makineleşme, sömürgecilik faaliyetleri, hammaddeye ulaşım ve yeni pazarlar oluşturulması, ticaret alanlarının genişlemesi, "sınıf" kavramının pratikleşmesi (burjuvazinin ve işçi sınıfının ortaya çıkışı), Fansız Devriminin ortaya koyduğu fikirler gibi bir çok etki sayesinde Sanayi devriminin oluştuğu ve etkilerinin toplumsal, sosyal ve ekonomik yaşam başta olmak üzere bir çok alana sirayet ettiğini vurgulamaktadır (s.21). Çalışma da ayrıca Sanayi Devriminin neden İngiltere'de ortaya çıtığı sorusuna da cevap aranmış ve şu nedenlere yer verilmiştir:

- 1215 Magna Charta ile İngiliz Parlamentosu'nun ticareti serbestleştirmesi

- Buluşların gerçekleştirilmesi

- Coğrafi koşulların ve sömürgecilik faaliyetlerinin varlığı

- Reformist hareketler sonrası artan okuryazarlı oranı ve Protestan Ahlak Anlayışı (s.23).

Çalışmanın ikinci bölümünü, Kurtuluş Yılmaz Genç hazırlamıştır (s. 109-150). Bu bölümde, İkinci Sanayi devrimi ekonomik, siyasal gelişmeler ışığında tartışılmıştır. Sanayi Devrimi, "teknoloji devrimi" olarakta adlandırılmakta ve 1860-1914 yılları arasını kapsamaktadır. İngiliz mucit H.Bessemer'in icat ettiği ucuz çelik üreteim yönteminin yaygılanlaştığı yıllar başlangıç olarak kabul edilmektedir. Disiplinler arası bir bakış açısının kullanıldığı bu bölümde siyasal, toplumsal ve ekonomik gelişmeler yönetim disiplini çerçevesi dahilinde tarihsel olarak ele alınmıştır. Genç, 1860 ve 1920'lerin sonu arasında yer alan ve 2.Sanayi devrimi olarak adlandırılan dönemde yaşanan teknolojik ve bilimsel gelişmelerin bu süreci oluşturduğunu ve bunun yanı sıra yönetim alanındaki gelişmelerin de katkısı olduğunun altını çizmektedir (s. 118). Bunun yanısıra özellikle 2.Sanai Devriminin üretimin 
altyapısında yaşanan köktenci dönüşümünde bu sürecin önemli gelişmeleri arasında olduğu vurgulanmaktadır.

Bu bölümde, yönetim kuramlarının tarihsel gelişimleri, Kimya başta olmak üzere çeşitli alanlarda yaşanan değişimler, Fordist üretim tarzı ve ABD'nin rolü, bu dönemdeki siyasal gelişmeler/örgütlenmeler ele alınmıştır. 2.Sanayi devriminin başlıca sonuçlarına ulaşılmıştır:

- Sanayi üretiminin artış1

- Üretimde verimlilik

- İşçi sınıfı mücadelesinin gelişmesi

- Kitlesel üretim ve yeni üretim yöntemlerinin oluşması vb. (s. 142).

Çalışmanının 3. bölümünde Kurtuluş Yılmaz Genç ve Metin Çakıroğlu 3. Sanayi Devrimi'ni okuyucuya sunmuşlardır (s.151-196). 3.Sanayi devrimi, önceki sanayi devrimlerinin ortaya koyduğu gelişmelerin ve ilgili birikimlerin bir sonucu olarak ortaya çıkmıştır. 3.Sanayi Devrimi, 20.yy. ilk yarısında başlamış ve bu yüzyılın sonuna kadar devam etmiştir. Kimi araştırmacılara göre 3.Sanayi devrimi ile 4.Sanayi devrimi arasında kesin bir geçiş çizgisinin bulunmadığını vurgulamaktadır. Bu bağlamıla, bu süreçlerin iç içe geçtiğini söylemek mümkündür.

Sanayi devrimi ile üretimde dijital devrim yaşanması, elektroniğin kullanımı ve bilgi teknolojilerinin geliştirilmesi ile birlikte üretim de otomatikleşmiştir. Özellikle 3D yazıcıların icadı ile araba parçalarının üretimi bir tuşla kitlesel hale getirilmiş olmaktadır.

Yazarlara göre, 3.Sanayi devrimi ile bilgi, bilgisayar ve iş fonksiyonları birbirleri ile bütünleşmiş ve böylelikle çalışan verimliliği artmıştır. Bu noktada "bilgi işçisi” kavramı ortaya çıkmıştır. Bu kavramın açıklanmasında ise 1.Sanayi Devrimi ve 2.Sanayi devriminde "yönetim alanında" yaşanan dönüşümler ve "çalışana" bakış açısı karşılaştırılmalı olarak verilmiştir (s.186). Ayrıca, Endüstri Toplumu ile Bilgi Toplumu arasındaki "yenilikçi teknoloji, sosyo-ekonomik yapı ve değerler" başlıkları altında farklılıklar/değişimler tablo halinde okuyucuya sunulmuştur (s.185).

Bölümde; 3.Sanayi Devriminin tanımı-gelişimi, yenilenebilir enerji, bilgi teknolojisi, bilgi iş̧̧isi gibi başlıklar ele alınmıştır.

Çalışmanin son bölümünde Cevdet Özmen, güncel bir tartışma olarak 4.Sanayi Devrimini ele almıştır (s.197-228). Almanya' da ulusal kalkınma projeleri içerisinde bir başlık olarak önerilen Endüstri 4.0 kavramı ve elde edilen teknolojik, bilimsel gelişmeler neticesinde yeni bir dönemin habercisi olmuştur. 2011 yılında Almanya'da Hannover Fuarı'nda kullanılan kavram, Alman hükümetinin üretim süreçlerini bilgisayarlaşma yöünde teşvik etmeye ve yüksek teknoloji ile donatması projesi olarak kabul edilen Endüstri 4.0 aynı zamanda 4.Sanayi devrimi anlamına gelmektedir. Özellikle, yapay zeka tartışmaları bu bağlamda Endüstri 4.0 sürecinin temelini teşkil etmektedir.

Yazar, Endüstri 4.0 sürecinin avantajlarını, eksikliklerini çeşitli yönleriyle ele almıştır.

Endüstri 4.0 ile birçok avantaja sahip olunacağı aşikardır. Bu noktada; sistemlerin denetlenmesi ve arıza tespitinin kolaylaşması, çevre dostu ve kaynak tasarrufu sağlayan sistemlerin kurulması, üretim esnekliğin artması, iş modellerinin geliştirilmesi, zaman ve mekandan bağımsız üretim gibi bir çok gelişim/değişimin avantaj sağlayacağı belirtilmektedir (s.214). Endüstri 4.0 ile birlikte çeşitli olumsuzlukların doğabileceği yazar tarafından dile getirilmiştir. Bu bağlamda; kontrolün makinelere geçmesi, istihdamın azalması, kültüren ve ekonomik yapıda yaşanması muhtemel değişimler, güvenlik açıkları, yalnızlaşma/yabancılaşma gibi bir çok olumsuzluğun yaşanabileceği örneklendirilmektedir (s.216).

Çalışmanın dikkat çeken başlıklarından birisi de "Türkiye Endüstri 4.0'a Hazırlık İçin Ne Yapabilir?"dir. Bu başlık altında yazar, Türkiye'nin 6 sektörde Endüstri 4.0 uygulamak için karar aldığını ve Ar-Ge çalışmalarının geliştirilmesi ile birlikte bu sayının arttırılması gerektiğini, okul müfredatlarının özellikle yazılım konularını içeren bir biçimde yeniden düzenlenmesi gerektiğini ve 
Endüstri 4.0 tanıtımına yönelik faaliyetlerin ülke genelinde yaygınlaştırılması gerektiğini ifade etmektedir (s. 219). ederim.

Sayın yazarlarımızı sosyal bilimler alanına katkı yapması muhtemel bu çalışmaları için tebrik

\section{KAYNAKÇA}

Genç, K. Y.; Çakıroğlu, M.; Özmen, C. ve Karadirek, G. (2019). Sanayi Devrimleri, Ankara: Gece Akademi. 